\title{
Solutions to some problems in the implementation of conjoint analysis
}

\author{
CAROL A. E. NICKERSON, GARY H. MCCLELLAND, and DOREEN M. PETERSEN \\ University of Colorado, Boulder, Colorado
}

\begin{abstract}
Methodological problems encountered in implementing conjoint analysis include (1) the impractically large set of multiattribute choice alternatives created by the factorial combination of more than a few attributes, (2) the hypothetical nature of the alternatives in the choice set, and (3) the assumption that each individual's preferences can be described by the same composition rule. The techniques of tailoring, belief matching, and axiom testing are suggested as solutions to these problems, and their use is demonstrated in a conjoint analysis study of individuals' contraceptive preferences. It is noted that tailoring and belief matching can also be used as methodological enhancements in functional measurement studies.
\end{abstract}

One of the major concerns of consumer research for the last decade has been the modeling of preferences for multiattribute choice alternatives. A variety of methodologies has been developed for preference modeling; perhaps the most popular is conjoint analysis, a value estimation technique developed primarily by Green and his associates (Green \& Rao, 1971; Green \& Wind, 1973, 1975). In conjoint analysis, different levels of a number of product attributes are factorially combined to create a set of hypothetical multiattribute choice alternatives, and the value of each alternative, product attribute, and product attribute level is estimated by various computer algorithms from an individual's preference ratings or rank ordering of the alternatives in the set.

Green, Rao, and DeSarbo (1978) and Green and Srinivasan (1978) discuss a number of methodological problems encountered in the implementation of conjoint analysis. These problems include (1) the impractically large set of multiattribute choice alternatives created by the factorial combination of more than a few attributes, (2) the hypothetical nature of the alternatives in the choice set, and (3) the assumption that each individual's preferences can be described by the same composition rule. The purpose of the present paper is to propose alternatives to the usual solutions to these problems. Specifically, it is suggested that (1) overly large choice sets can be avoided if the choice set is "tailored" to each individual by combining only those few attributes that he or she considers most important; (2) preferences for real alternatives can be studied by "matching" each real alternative of interest

\footnotetext{
Preparation of this paper was supported in part by Grant HD-14403 from the National Institute of Child Health and Human Development. The assistance and suggestions of Sarah Gaskill, Alice Healy, Lou McClelland, Michael $O^{\prime}$ Reilly, and several reviewers are greatly appreciated. Requests for reprints should be sent to the Publications Librarian, Center for Research on Judgment and Policy, Muenzinger Psychology Building, University of Colorado, Boulder, CO 80309-0344.
}

to one of the hypothetical choice alternatives on the basis of the individual's beliefs about the real alternative; and (3) a variety of composition rules can be tested if the usual conjoint analysis procedures are preceded by "axiom tests." A more detailed discussion of these strategies is provided below, followed by a demonstration of their use in a conjoint analysis study of contraceptive preference.

\section{Generation of the Choice Alternatives}

Generation of the multiattribute choice alternatives for conjoint analysis is often a most difficult task. The existence of substantial individual variation in values assigned to product attributes often means that a large number of attributes must be considered if one wants to be able to predict consumer preferences reasonably well. In addition, there are usually at least three or four levels of each product attribute that are of interest to the consumer researcher. These levels must be combined in an orthogonal factorial design if value estimation is to be accurate. The factorial combination of three or four levels of several attributes obviously creates a very large set of multiattribute choice alternatives. However, in order to maintain respondent interest and avoid "information overload," it is recommended that an individual be presented with no more than about 30 choice alternatives (Green \& Srinivasan, 1978). Green (1974) has suggested the use of various fractional factorial designs to reduce the number of choice alternatives while still maintaining orthogonality. The difficulty with this solution is that as the ratio of the number of alternatives to the number of estimated parameters (i.e., the number of attribute levels summed over all attributes) decreases, prediction error increases (Darlington, 1968). With the sparse fractional factorial designs necessary to accommodate the inclusion of a large number of product attributes, value estimation may be quite unreliable.

A possible solution to the problem of alternative generation stems from the observation that not every attribute included in a factorial design is likely to be important to 
every respondent. Indeed, psychological research on cognitive limitations suggests that it is probably not even possible for an individual to consider more than a few product attributes. (See Abelson and Levi, 1985, for a brief review of recent research.) Fishbein (1967) noted that the inclusion of nonsalient attributes in an attitude model tends to reduce the precision of attitude measurement, and consumer researchers generally agree that only salient attributes should be included (Wilkie \& Weinreich, 1972). Most consumer researchers seem to assume that their sets of attributes, generally five to seven iil number, are sufficiently and exhaustively salient for all respondents. Hansen (1969), however, reported that the predictive power of a model was not diminished when only the three most important attributes of a larger set were used. Wilkie and Weinreich (1972) conducted a series of studies in which they allowed both the number of attributes and the attributes themselves to vary across respondents and concluded that maximal predictive power was obtained with an average of 2.5 to 3.6 attributes taken from a larger set. These results suggest that although a large number of attributes may be needed to predict reasonably well the preferences of a group of respondents, any single respondent's preferences may be predicted accurately using only those few attributes that he or she considers most important. One solution to the problem of multiattribute choice alternative generation, then, is to tailor the set of alternatives to each respondent by factorially combining only those two or three attributes that he or she considers most important. This tailoring technique is used in the present study to create an individual set of choice alternatives for each respondent.

\section{Matching Real to Hypothetical Alternatives}

The multiattribute choice alternatives used in conjoint analysis are usually hypothetical, for several reasons. First, the number of real products in a product class is often very small. Second, real products may not be distinctive enough to provide reliable value estimates. Third, reliable value estimates require orthogonal factorial designs, and no set of real products fulfills this requirement. The use of hypothetical choice alternatives means that conjoint analysis emphasizes the role of values and neglects the role of beliefs in determining preferences, although the decision-making models developed by psychologists and economists have stressed that preferences are determined by beliefs as well as by values. With hypothetical choice alternatives formed by the factorial combination of varying levels of product attributes, beliefs about each alternative are held constant across individuals. That is, the beliefs that an individual holds about a multiattribute choice alternative are the attribute levels used to describe that alternative, and these beliefs must therefore be the same across all individuals. Holding beliefs constant prevents them from interacting with values to determine preferences. For many applications, particularly those concerned with the development of new or improved products, this neglect of beliefs is not a problem because the major interest is in determination of the most valued attributes of those products.

However, relying solely on value estimation in determining preferences for existing products such as contraceptive methods is likely to be inadequate. Beliefs about real products undoubtedly play a large role in determining product acceptability. For example, a woman who values convenience but believes the diaphragm to be inconvenient is unlikely to use the diaphragm. In modeling individuals' preferences for vacation sites, Green et al. (1978) and Green and Srinivasan (1978) recognized the necessity of including beliefs as well as values in the development of preference models for real products. However, it is generally accepted among consumer researchers that "perceptual judgments" (beliefs) are much more homogeneous than "preference judgments" (values) (Parker \& Srinivasan, 1976). Therefore, although the values included in each individual's preference model were his or her own, the beliefs included in that model were not the beliefs of the individual but instead were group estimates. This practice ignores the possibility that individuals' beliefs about real products can, and probably do, vary greatly.

A "belief-matching"' technique (e.g., Holbrook, Moore, Dodgen, \& Havlena, 1985; Moore \& Holbrook, 1982; Nickerson \& McClelland, 1988; Schuler \& Prosperi, 1978; Wittink \& Montgomery, 1979) can be used to incorporate an individual's own beliefs into his or her preference model. This technique involves designing a set of hypothetical multiattribute choice alternatives from product attributes with realistic product levels and then matching each real product of interest to one of the hypothetical alternatives on the basis of the individual's beliefs about the real product. Belief matching allows one to gauge the extent of individual differences in beliefs that may be affecting product preferences. It also allows one to determine the extent to which the hypothetical product attributes and attribute levels accurately reflect an individual's beliefs about the real products. In the present study, this belief-matching technique is used to incorporate beliefs into the modeling of individuals' preferences.

\section{Assumption of Identical Composition Rules}

The preference model underlying conjoint analysis posits that an individual's evaluation of a product is a function of his or her values or "part worths" for the levels of the attributes describing that product. The function describing how an individual combines part worths to form an overall product evaluation is called the "composition rule." The typical application of conjoint analysis recognizes that there is considerable across-individual variation in values for products, product attributes, and product attribute levels, and therefore usually performs a separate analysis for each individual (although group analyses are by no means uncommon). However, it is nearly always assumed that all individuals use the same composition rule, and that that composition rule is additive over all attributes in the study (Green \& Srinivasan, 
1978). It is also generally assumed that the conjoint analysis computer algorithm's goodness-of-fit (or badness-offit) measure will detect deviations from additivity that may occur either because the composition rule is not in fact additive or because of the presence of random response error.

These assumptions are not warranted. It is possible that the assumed additive composition rule may not be appropriate for some individuals. In some cases, the goodness- or badness-of-fit measure will detect a nonadditive composition rule; in other cases, however, it will not. Busemeyer (1980), Green and Wind (1973), and Nygren (1980) have noted that conjoint analysis cannot detect interactive composition rules, and Timmermans (1980) has shown that it fails to detect other composition rules as well. Nickerson and McClelland (1984) demonstrated that the badness-of-fit measure "stress" could equal zero when the composition rule was conjunctive/ additive or interactive, even though a stress of zero theoretically indicates perfect adherence to an additive composition rule. They also showed that the stress measure fails to detect some random response errors, such as adjacent pair reversals and outliers, and cannot diagnose attributes that are "inessential" or irrelevant to the individual's preferences.

The inability of conjoint analysis to detect nonadditive composition rules, random response error, and inessential attributes has been suggested by others as well (Louviere, 1988, p. 26; Srinivasan \& Shocker, 1973; Takane, 1978). More generally, Anderson and Shanteau (1977), Birnbaum (1973), Shanteau (1977), and Zeleny (1976) have decried the use of goodness-of-fit measures, such as correlation coefficients, as indices of model fit. Their studies have provided compelling demonstrations that correlations between theoretical or mathematical models and simulated (error-free) or real (error-containing) data can be very high, even when the assumed composition rule is incorrect.

Despite these caveats, most researchers using conjoint analysis appear to be satisfied with its performance, probably because of an interest in prediction rather than explanation. The belief is that conjoint analysis provides good prediction even when there is random response error or when the assumed composition rule is invalid, because linear compensatory composition rules are quite robust and can approximate the outcomes of other composition rules quite well (Dawes \& Corrigan, 1974; Green \& Srinivasan, 1978; Yntema \& Torgerson, 1961). Indeed, the inability of conjoint analysis to detect nonadditive composition rules, random response error, and inessential attributes would not be serious if these problems had little or no impact on value estimation. It is not generally recognized, however, that value estimation can be extremely sensitive to deviations from perfect additivity (Carroll, 1973; Kruskal, 1965; Srinivasan \& Shocker, 1973). For example, Nickerson and McClelland (1984) demonstrated that the introduction of a single outlier into an otherwise perfectly additive data set changed the values (relative importance percentages) associated with three attributes from $5 \%, 59 \%$, and $36 \%$ to $0 \%, 100 \%$, and $0 \%$, respectively.
Nickerson and McClelland (1984) and Nygren (1985) have suggested that the misestimation of values can be avoided by preceding conjoint analysis (or, as it is sometimes called, "numerical conjoint measurement") with axiomatic conjoint measurement. Axiomatic conjoint measurement does not depend on a goodness- or badness-offit statistic, but instead tests the qualitative properties or "'axioms"' that a preference rank ordering of alternatives must satisfy if it is to be represented numerically according to a proposed composition rule (Krantz, Luce, Suppes, \& Tversky, 1971; Krantz \& Tversky, 1971). Unlike conjoint analysis, the axiomatic technique can detect nonadditive composition rules, random response error, and inessential attributes. These problems can then be corrected before conjoint analysis is performed, thereby eliminating the misestimation of values. In the present study, conjoint analysis is preceded by axiomatic conjoint measurement.

In summary, tailoring seems an appropriate strategy when there are a large number of possible product attributes that individuals might value; belief matching seems an appropriate strategy when there may be individual differences in beliefs about the products under consideration; and axiomatic conjoint measurement followed by conjoint analysis seems an appropriate strategy when there may be individual differences in composition rules or when the data are not error-free. There are undoubtedly many different kinds of consumer products and services that fit these criteria; in the present study, the modeling of individuals' preferences for a variety of contraceptive methods is used to demonstrate the application of these three techniques.

\section{METHOD}

\section{Respondents}

One hundred and fifty-six students (both men and women) enrolled in an introductory psychology course at the University of Colorado at Boulder participated in this study in partial fulfillment of course requirements. This convenience sample was considered appropriate because contraception is a relevant issue for college students and because the primary purpose of this study is a methodological demonstration rather than the presentation of substantive results per se. However, because college students may not be representative of contraceptive users (or potential users) in general, the substantive results should not be generalized to any population other than college students.

\section{Materials and Procedure}

There are many contraceptive attributes that an individual might consider important: (1) simplicity or convenience of use, (2) effectiveness in preventing pregnancy, (3) costs (initial and continuing), (4) required frequency of use or duration of contraceptive effect, (5) permanence or reversibility, (6) means of administration (e.g., ingestion, implantation, insertion), (7) legal, moral, and religious concerns, (8) responsibility for use (man, woman, 
both partners), (9) circumstance of use (coitus-related or coitus-independent), (10) possible health benefits (e.g., regulation of the menstrual cycle), (11) protection of privacy or modesty, (12) effects on sexual satisfaction or pleasure, (13) mode of action (e.g., chemical, mechanical, surgical), (14) psychological effects (e.g., embarrassment), (15) safety or lack of harmful health side effects, (16) physical properties (e.g., the taste of contraceptive foam), (17) the means whereby a method is obtained (e.g., over-the-counter at a drugstore, visit to a physician), and perhaps others (Boston Women's Heaith Book Collective, 1976, pp. 181-215; Campbell \& Berelson, 1971; Cohen, Severy, \& Ahtola, 1978; Polgar \& Marshall, 1976; Salyer \& Bausch, 1978, pp. 6-7).

As this paper is intended to be a demonstration study, it was decided for expositional simplicity to reduce this large set of attributes to a smaller set to serve as the basis for tailoring. The attributes in the reduced set include (1) convenience, (2) effectiveness, (5) reversibility, (8) use, (15) side effects, and (17) type. These particular attributes were selected because they seem to reflect the concerns most often expressed in the contraceptive information pamphlets and booklets distributed by familyplanning clinics and women's health-care groups. It is important to note, however, that any other subset of the attributes, or even the entire set, could have been selected for study.

Convenience refers to the degree of difficulty experienced in obtaining and using a birth control method; it involves such considerations as whether or not the method requires a daily routine, whether or not the method requires preparation immediately before intercourse or interruption of sexual activity, and whether or not the method is "messy." Effectiveness is defined in terms of the percentage of women per year who become pregnant while using a birth control method. Reversibility refers to the possibility of being able to bear children after discontinuing use of a birth control method. Effectiveness and reversibility were combined into a single attribute because pilot studies indicated that although effectiveness and reversibility are conceptually distinct attributes of contraceptive use, they are in actuality highly related attributes; most respondents were aware that the most effective of the currently existing birth control methods are also irreversible, whereas all the less effective methods are reversible. (Combining attributes is common in conjoint analysis studies; when there is a large number of attributes, factor analysis can be used to determine those that are highly related to one another.) Use refers to the partner-the man, the woman, or both-who actually uses a birth control method. Side effects is defined as the possible present and future risks to an individual's health that using a birth control method entails. Type concerns the manner in which a birth control method is obtained; for example, a method may require surgery, may require one or more visits to a physician or clinic, may be purchased at the drug counter without a prescription, or may be "natural." A possible sixth attribute, costs, was not included because pilot studies showed that respondents either do not consider the cost of a birth control method to be important or believe that birth control methods do not vary much in overall cost. Without such variance, the attribute costs cannot be used to discriminate between birth control methods and therefore cannot increase predictive power, regardless of its importance.

Each respondent attended two experimental sessions. At the first session, each respondent was given an information sheet describing the five contraceptive attributes and asked to indicate the two or three attributes that he or she would consider most important in choosing a birth control method. A questionnaire was then generated by computer for each respondent on the basis of his or her chosen attributes. There are 20 different possible combinations of two or three attributes chosen from a set of five; thus, there were 20 different questionnaires. Each questionnaire consisted of three tasks that the respondent completed at a second experimental session.

As the first task (the real birth control ranking task), each respondent was given a list of the nine most popular birth control methods currently available: (1) tubal ligation, (2) intrauterine device, (3) vasectomy, (4) pill, (5) condom, (6) diaphragm, (7) vaginal foam/cream/jelly, (8) periodic abstinence, and (9) condom with foam/cream/ jelly. Each method listed was accompanied by a short description that made no mention of its convenience, effectiveness-reversibility, use, side effects, or type, insofar as these attributes are not obvious. For example, the diaphragm was described as "a thin rubber dome holding a sperm-killing cream or jelly that is inserted into the vagina to cover the cervix and prevent sperm from entering the uterus." The respondent was asked to rank order the nine birth control methods from "most preferred" to "least preferred" as if he or she "did not want a child just yet but might want a child or children in the future."

It may seem odd that a respondent asked to imagine that he or she "did not want a child just yet but might want a child or children in the future" would be offered tubal ligation and vasectomy as choice alternatives. Tubal ligation and vasectomy were included because they are among the birth control methods currently available, and it is possible that an individual would prefer an irreversible method to an ineffective one. This might happen, for instance, if an individual were ambivalent about having children and would rather not have any children at all than risk having one now by using a less effective birth control method.

Three or four levels of each contraceptive attribute were selected so that the most popular birth control methods currently available might reasonably be characterized by one level of each attribute. These levels, and their verbal descriptions, are shown in Table 1. For the second task (the hypothetical contraceptive ranking task), the levels of the two or three contraceptive attributes chosen by the respondent were factorially combined to form a set of 
Table 1

Levels of the Five Contraceptive Attributes

\begin{tabular}{|c|c|c|}
\hline Attribute & Level & Description \\
\hline Convenience & $\begin{array}{l}\text { (1) convenient } \\
\text { (2) somewhat inconvenient } \\
\text { (3) inconvenient }\end{array}$ & [self explanatory] \\
\hline \multirow[t]{3}{*}{$\begin{array}{l}\text { Effectiveness- } \\
\text { reversibility }\end{array}$} & $\begin{array}{l}\text { (1) } 98 \% \text { to } 100 \% \text { effective } \\
\text { and not reversible }\end{array}$ & $\begin{array}{l}1 \text { to } 2 \text { women out of } 100 \text { will have accidental } \\
\text { pregnancies in a year; once started, the } \\
\text { use of this method cannot be discontinued }\end{array}$ \\
\hline & $\begin{array}{l}\text { (2) } 95 \% \text { to } 99 \% \text { effective } \\
\text { and reversible }\end{array}$ & $\begin{array}{l}1 \text { to } 5 \text { women out of } 100 \text { will have accidental } \\
\text { pregnancies in a year; one can nearly always } \\
\text { stop using this method and then have children }\end{array}$ \\
\hline & $\begin{array}{l}\text { (3) } 75 \% \text { to } 90 \% \text { effective } \\
\text { and reversible }\end{array}$ & $\begin{array}{l}10 \text { to } 25 \text { women out of } 100 \text { will have accidental } \\
\text { pregnancies in a year; one can nearly always } \\
\text { stop using this method and then have children }\end{array}$ \\
\hline \multirow[t]{3}{*}{ Use } & (1) man & [self explanatory] \\
\hline & (2) woman & \\
\hline & (3) both & \\
\hline \multirow[t]{3}{*}{ Side effects } & (1) none/minor & $\begin{array}{l}\text { virtually no side effects at all; those } \\
\text { that do occur are minor }\end{array}$ \\
\hline & (2) minor & $\begin{array}{l}\text { possible minor side effects (a nuisance, but } \\
\text { not dangerous) }\end{array}$ \\
\hline & (3) $\mathrm{minor} / \mathrm{major}$ & $\begin{array}{l}\text { possible minor side effects and a risk of } \\
\text { major (damaging to health) side effects }\end{array}$ \\
\hline \multirow[t]{4}{*}{ Type } & (1) surgery & requires surgery \\
\hline & (2) physician/clinic & $\begin{array}{l}\text { nonsurgical but requires a visit(s) to a } \\
\text { physician or clinic }\end{array}$ \\
\hline & (3) drugstore & $\begin{array}{l}\text { can be obtained over the counter (without } \\
\text { a prescription) at a drugstore }\end{array}$ \\
\hline & (4) natural & $\begin{array}{l}\text { requires no surgery, no visits to a physician } \\
\text { or clinic, and no prescription or } \\
\text { nonprescription drugs or devices }\end{array}$ \\
\hline
\end{tabular}

hypothetical multiattribute contraceptive choice alternatives. The number of choice alternatives ranged from 9 (for a $3 \times 3$ design such as that formed by factorially combining the levels of convenience and side effects) to 36 (for a $3 \times 3 \times 4$ design such as that formed by factorially combining the levels of effectiveness-reversibility, side effects, and type). Each choice alternative was printed on a separate card, and the respondent was instructed to rank order the cards from "most preferred" to "least preferred" contraceptive as if he or she "did not want a child just yet but might want a child or children in the future." Respondents could refer to descriptions of their selected attributes and attribute levels while performing the ranking task.

As the third task (the belief task), each respondent was asked to indicate the level of each of his or her chosen contraceptive attributes that he or she believed to be the most accurate description of each of the nine real birth control methods. Thus a respondent who chose effectiveness-reversibility, side effects, and type as her most important attributes might indicate that she believes that the diaphragm is " $95 \%$ to $99 \%$ effective and reversible," entails "possible minor side effects," and "can be obtained over the counter at a drugstore."

\section{RESULTS}

Individual differences in consumer preferences for real products are the result of individual differences in beliefs about the attributes of those products, individual differences in values for those attributes, and/or individual differences in the ways beliefs and values are combined across attributes to form an overall evaluation of each product. The three proposed methodological enhancements to conjoint analysis are necessitated by these individual differences. Accordingly, the presentation of the analysis and results has been structured to answer the following questions:

1. Are there individual differences in the attributes regarded as most important in choosing a contraceptive method?

2. Are there individual differences in composition rules?

3. Are there individual differences in the values assigned to each contraceptive attribute?

4. Are there individual differences in beliefs about real birth control methods?

5. How well do beliefs, values, and composition rules predict individuals' preferences for real birth control methods? 
The answers to the first and third questions demonstrate the use of tailored multiattribute choice alternatives, the answers to the second and third questions demonstrate the use of axiom testing followed by traditional conjoint analysis, and the answers to the fourth and fifth questions demonstrate the use of the belief-matching technique.

\section{Most Important Attributes}

Ninety-three of the 156 respondents chose convenience, effectiveness-reversibility, and side effects as their most important attributes, 19 chose effectiveness-reversibility and side effects, and 26 chose effectiveness-reversibility, side effects, and type. The remaining 18 respondents' choices were scattered over 8 of the other 17 possible twoor three-attribute combinations, as shown in Table 2 . In terms of single attributes, effectiveness-reversibility, side effects, convenience, type, and use were chosen by 148 , $148,106,35$, and 6 respondents, respectively, as one of their two or three most important attributes.

\section{Composition Rules}

The first step in the analysis of each respondent's data consists of determining his or her composition rule. A composition rule is a mathematical equation that describes how an individual combines his or her values for the levels of the attributes describing a multiattribute choice alternative in forming an overall evaluation of that alternative. The simplest composition rule is an additive one over all the attributes selected by the respondent; if the respondent selected attributes $K, L$, and $M$, then an additive composition rule would be expressed as $\mathrm{K}+\mathrm{L}+\mathrm{M}$. Axiomatic conjoint measurement can detect a variety of composition rules, including additive rules over two or three attributes, distributive rules $[(K+L) \times M]$, and dual-distributive rules $(K \times \mathbf{L}+\mathbf{M})$. It can also detect variants of these rules, such as additive rules for three

Table 2

Attribute Combinations

\begin{tabular}{cc}
\hline Combination & $n$ \\
\hline CE & 3 \\
CU & 0 \\
CS & 1 \\
CT & 0 \\
EU & 0 \\
ES & 19 \\
ET & 0 \\
US & 0 \\
UT & 0 \\
ST & 2 \\
CRU & 2 \\
CRS & 93 \\
CET & 2 \\
CUS & 0 \\
CUT & 1 \\
CST & 4 \\
EUS & 3 \\
EUT & 0 \\
EST & 26 \\
UST & 0 \\
\hline
\end{tabular}

Note $-\mathrm{C}=$ convenience, $\mathrm{E}=$ effectiveness-reversibility, $\mathrm{U}=$ use, $S=$ side effects, $T=$ type. attributes in which one or two of those attributes are irrelevant to the respondent's preferences, distributive rules in which the three attributes are permuted, and multiplicative rules $(\mathrm{K} \times \mathrm{L} \times \mathrm{M}) .{ }^{1}$ Ordinarily, the additive composition rule is proposed and tested first; if it is rejected, other composition rules are considered sequentially (Krantz et al., 1971; Krantz \& Tversky, 1971).

In axiomatic conjoint measurement, a proposed composition rule is tested by determining whether the rank ordering of the multiattribute alternatives in the choice set satisfies certain qualitative properties called axioms. For example, the composition rule for a set of alternatives created by a $3 \times 3 \times 3$ factorial design is additive if the rank ordering of those alternatives satisfies the axioms of (1) simple independence, (2) joint independence, and (3) double cancellation. Simple independence means that the ordering of the levels of each attribute must be invariant over every combination of the levels of the other two attributes. For example, consider a respondent who selected convenience, effectiveness-reversibility, and side effects as his or her three most important contraceptive attributes. In order to satisfy simple independence, the respondent's rank ordering of the 27 alternatives in the choice set must be such that (1) the ordering of the three levels of convenience is the same for each of the nine possible combinations of the levels of effectiveness-reversibility and side effects, (2) the ordering of the three levels of effectiveness-reversibility is the same for each of the nine possible combinations of the levels of convenience and side effects, and (3) the ordering of the three levels of side effects is the same for each of the nine possible combinations of the levels of convenience and effectiveness-reversibility. Joint independence means that the ordering of every combination of the levels of any two attributes must be invariant over each level of the third attribute. To satisfy joint independence, the above respondent's ranking of the 27 alternatives must be such that (1) the ordering of the nine combinations of the levels of convenience and effectiveness-reversibility is the same at each of the three levels of side effects, (2) the ordering of the nine combinations of the levels of convenience and side effects is the same at each of the three levels of effectiveness-reversibility, and (3) the ordering of the nine combinations of the levels of effectiveness-reversibility and side effects is the same at each of the three levels of convenience. Double cancellation has no simple intuitive explanation but is rarely violated when the ranking satisfies both simple and joint independence. Space considerations prevent a more detailed discussion of the various composition rules and axioms; a theoretical and mathematically sophisticated treatment can be found in Krantz et al. (1971). Summaries are available in C. H. Coombs, Dawes, and Tversky (1970) and Krantz and Tversky (1971). Barron (1977), Curley (1990), and Nickerson and McClelland (1988) offer tutorials for the more practically oriented.

Real-world data are typically fallible, and any evaluation of the validity of a proposed composition rule should take the possibility of error into account (Krantz \& Tversky, 
1971). Requiring a rank ordering to satisfy perfectly the axioms of a proposed composition rule is unrealistic; it is analogous to rejecting the proposed model in a correlational study if the correlation coefficient is less than 1.00. Unfortunately, an error theory that specifies the number and type of axiom violations that should cause rejection of a proposed composition rule has not yet been developed for axiomatic conjoint measurement. A common solution to this problem is to allow a small, prespecified number of nonsystematic errors before rejecting the proposed composition rule (C. H. Coombs \& Bowen, 1971; C. H. Coombs, L. C. Coombs, \& McClelland, 1975; L. C. Coombs, 1979; Nickerson \& McClelland, 1988; Ullrich \& Painter, 1974). This solution was adopted in the present study; one error was allowed for 9- and 12alternative choice sets, and up to four errors were allowed for 27-and 36-alternative choice sets, before rejection of the proposed composition rule. These error criteria are stringent given the possible number of errors that might be made (McClelland, 1977; Nygren, 1985).

An error was defined as (1) the reversal of a pair of alternatives with adjacent ranks or (2) an alternative that was clearly misplaced in the ordered card deck. As an example of a pair-reversal error, consider two choice alternatives that differ only in their levels of the convenience attribute. The more preferred alternative, with a rank of 21 , is "somewhat inconvenient," whereas the less preferred alternative, with a rank of 20 , is "convenient." 2 This preference pattern probably represents an ordering mistake by the respondent if in all other such adjacent pairs of alternatives the "convenient" alternative is preferred to the one that is "somewhat inconvenient." A misplaced alternative is an outlier or one whose placement in the rank ordering of the set of alternatives is highly suspect. For example, a rank ordering with numerous axiom violations may satisfy additivity perfectly if the least preferred alternative, ranked 1 , is either eliminated or inserted into the ranking between, say, the two alternatives with ranks of 15 and 14. This type of pattern suggests that the respondent inadvertently omitted a card while performing the card-ordering task and simply placed it at the back of the card deck after having completed the task.

It is simple but tedious and time-consuming to determine by hand whether or not a preference rank ordering satisfies the axioms of a proposed composition rule; therefore, a computer program such as CMSCAL (Nygren, 1986), CONJOINT (Holt \& Wallsten, 1974), or PCJM (Ullrich \& Cummins, 1973; Ullrich, Cummins, \& Walkenbach, 1978) is usually used. In this study, proposed composition rules were tested using a revised version of the PCJM program (PCJM2, Ullich et al., 1978). The PCJM analyses show that the preference rank orderings of the hypothetical contraceptive alternatives of 128 of the 156 respondents are consistent with one of five main types of composition rules: additive over all attributes selected, additive with one attribute inessential, one-attribute, conjunctive/additive over all attributes selected, and conjunctive/additive with one attribute inessential. Each of these types is defined below; their frequency distribution is shown in Table 3.

The preference rank orderings of all 25 respondents who selected two attributes and of 48 of the 131 respondents who selected three attributes satisfied the additivity axioms for all attributes selected. The composition rules of these 73 respondents are classified as "additive over all chosen attributes" in Table 3.

An additional 9 respondents produced rank orderings that satisfied the additivity axioms for two of the three attributes they selected. The rank orderings showed that these respondents were indifferent to the third attribute, even though they chose it as important. The composition rules of these respondents are classified as "additive with one attribute inessential" (C. H. Coombs et al., 1975, p. 285; Krantz et al., 1971, p. 256). The composition rules of an additional 8 respondents who were indifferent to two of the three selected attributes are classified as "oneattribute" rules. These rules might also be considered "additive with two attributes inessential"; however, they are not additive in the strict sense because two or more attributes are required for additivity.

For 36 of the respondents who chose three attributes, the 9 or 12 least preferred alternatives-all described by the least desirable level of one attribute-were randomly ordered, with the preference ordering of the remaining alternatives satisfying the additivity axioms. The composition rules of these respondents are classified as "conjunctive/ additive over all chosen attributes." It appears that these respondents first set aside the least preferred alternatives without ordering them (for example, the 9 alternatives whose use entails "minor/major side effects" in a convenience, effectiveness-reversibility, and side effects attribute combination), then ordered the remaining contraceptive alternatives consistent with an additive composition rule (Nickerson \& McClelland, 1984, 1988). The composition rules of 2 additional respondents are classified as "conjunctive/additive with one attribute inessential." The unacceptable attribute levels for all 38 respondents are shown in Table 3. Not surprisingly, the most common unacceptable attribute level is " $98 \%$ to $100 \%$ effective and not reversible."

The preference rankings of the remaining 28 respondents did not satisfy the axioms of any of the proposed composition rules. These respondents were eliminated from subsequent analysis because the derivation of accurate values requires the validation of a composition rule.

\section{Values}

Given a preference rank ordering that satisfies perfectly the necessary axioms for the proposed composition rule, various computer programs can be used to estimate a respondent's values for each attribute and attribute level. If the rank ordering does not satisfy the axioms because of a small amount of random response error, inessential attributes, or conjunctivity, error correction must be applied to the rank ordering prior to value estimation. For example, if the rank ordering would satisfy the axioms 
Table 3

Classification of Composition Rules

\begin{tabular}{|c|c|c|c|}
\hline Composition Rule/Attributes/Unacceptable Levels & & $n$ & \\
\hline $\begin{array}{l}\text { Additive over all chosen attributes } \\
\text { CE } \\
\text { CS } \\
\text { ES } \\
\text { ST } \\
\text { CES } \\
\text { EST }\end{array}$ & 73 & $\begin{array}{r}3 \\
1 \\
19 \\
2 \\
38 \\
10\end{array}$ & \\
\hline $\begin{array}{l}\text { Additive, one attribute inessential } \\
\text { CU(E) } \\
\text { ES(C) } \\
\text { CE(S) } \\
\text { ST(C) } \\
\text { ES(U) } \\
\text { ES(T) }\end{array}$ & 9 & $\begin{array}{l}1 \\
2 \\
1 \\
1 \\
1 \\
3\end{array}$ & \\
\hline $\begin{array}{l}\text { One-attribute } \\
\text { E(SC) } \\
\text { C(ES) } \\
\text { S(CE) } \\
\text { E(US) } \\
\text { E(ST) }\end{array}$ & 8 & $\begin{array}{l}2 \\
2 \\
1 \\
1 \\
2\end{array}$ & \\
\hline $\begin{array}{l}\text { Conjunctive/additive over all chosen attributes } \\
\text { CEU } \\
\text { " } 98 \% \text { to } 100 \% \text { effective and not reversible" }\end{array}$ & 36 & 1 & 1 \\
\hline $\begin{array}{l}\text { CES } \\
\text { " } 98 \% \text { to } 100 \% \text { effective and not reversible" } \\
\text { "minor/major side effects"' }\end{array}$ & & 29 & $\begin{array}{r}25 \\
4\end{array}$ \\
\hline $\begin{array}{l}\text { CET } \\
\text { "requires surgery" }\end{array}$ & & 1 & 1 \\
\hline $\begin{array}{l}\text { CST } \\
\text { "minor/major side effects" }\end{array}$ & & 1 & 1 \\
\hline $\begin{array}{l}\text { EST } \\
\text { "98\% to } 100 \% \text { effective and not reversible" } \\
\text { "75\% to } 90 \% \text { effective and reversible" } \\
\text { "minor/major side effects" }\end{array}$ & & 4 & $\begin{array}{l}1 \\
1 \\
2\end{array}$ \\
\hline $\begin{array}{l}\text { Conjunctive/additive, one attribute inessential } \\
\text { CE(S) } \\
\text { " } 98 \% \text { to } 100 \% \text { effective and not reversible" }\end{array}$ & 2 & 1 & 1 \\
\hline $\begin{array}{l}\mathrm{CT}(\mathrm{U}) \\
\text { "requires surgery" }\end{array}$ & & 1 & 1 \\
\hline Not classified & 28 & & \\
\hline
\end{tabular}

Note- $\mathrm{C}=$ convenience, $\mathrm{E}=$ effectiveness-reversibility, $\mathrm{U}=$ use, $\mathrm{S}=$ side effects, $\mathrm{T}=$ type. Attributes in parentheses represent inessential attributes. Attribute levels in quotes represent the unacceptable attribute levels in conjunctive/additive rules.

for three-attribute additivity were it not for one misplaced choice alternative, that alternative is eliminated from the rank ordering prior to value estimation. (For a more complete discussion of error correction, see Nickerson and McClelland, 1984.) ${ }^{3}$

Available value-estimation programs for additive and additive-variant rules include ADDALS (de Leeuw, Young, \& Takane, 1976), OPSCOLES (Emery, 1978), NMRG (Johnson, 1975), MONANOVA (Kruskal, 1965), ORDMET (McClelland \& C. H. Coombs, 1975), UNICON (Roskam, 1974), and POLYCON (Young, 1972). DIST (Emery, 1977a) and DULST (Emery, 1977b) can be used for distributive and dual-distributive rules, respectively. In the present study, MONANOVA was used to estimate values for all 128 respondents for whom composition rules could be determined because all rules were either additive or additive-variant.
Attribute values are expressed as relative importance percentages and can vary from $0 \%$ to $100 \%$. Inessential attributes have estimated values of $0 \%$. Presumably, unchosen attributes have values between $0 \%$ and the value estimated for the least important of the chosen attributes. This value is not known, of course, so for the purposes of additional analysis unchosen attributes were assigned values of $0 \%$. It is important to note that an attribute's value is dependent on the set of attributes and attribute levels being considered and might change if different attributes and/or attribute levels were to be used. As an extreme example, consider the likely effect on an individual's value for the side effects attribute if its third level were changed to "almost certainly shortens life expectancy by 15 years." Attribute values can also change depending on the purpose for which a contraceptive method is being chosen. For instance, an individual's values for 
effectiveness-reversibility may vary depending on whether she wishes to postpone or to cease childbearing.

The values of the five contraceptive attributes vary widely for the 128 respondents for whom composition rules could be determined. A cluster analysis over respondents using the attribute values as respondent descriptors (BMDP2M, Dixon \& Brown, 1977) produced 3 major and 13 smaller clusters of respondents. The 3 major clusters are described by the box-and-whisker plots (Tukey, 1977, pp. 39-41) in Figure 1. In these plots, the endpoints of the "whiskers" represent the minimum and maximum attribute values in a given cluster, the vertical line represents the median, and the "box" encloses the interquartile range.

Exactly half of the 128 respondents are contained in the largest cluster. These respondents are moderately concerned about effectiveness-reversibility (median value of $59 \%$ ), somewhat concerned about side effects (30\%), and only slightly or not-at-all concerned about convenience, use, or type $(9 \%, 0 \%$, and $0 \%$, respectively). Respondents in a second cluster $(n=19)$ are also moderately concerned about effectiveness-reversibility (62\%), but are somewhat concerned about convenience $(31 \%)$, with little or no concern about use, side effects, or type $(0 \%$, $8 \%$, and $0 \%$, respectively). Respondents in the third cluster $(n=19)$ are primarily concerned about side effects $(55 \%)$, somewhat concerned about effectivenessreversibility $(37 \%)$, and show little or no concern about convenience, use, or type $(7 \%, 0 \%$, and $0 \%$, respectively). The 13 smaller clusters each consist of 1 or a few respondents with other values for the five contraceptive attributes and will not be described here. Both the existence of a large number of clusters and the fact that the attribute values are homogeneous within clusters but heterogeneous across clusters are evidence of large individual differences in contraceptive values.

\section{Beliefs}

The determination and validation of an individual's beliefs about the attributes of each of the nine real birth control methods is a three-step procedure. First, the overall evaluation of each hypothetical contraceptive alternative is computed by combining, according to the appropriate composition rule, the values of the attribute levels describing that alternative.

Second, each real birth control method is matched, using the information obtained in the belief task, to one of the hypothetical contraceptive alternatives and given that alternative's evaluation. For example, if a respondent indicated that he or she believes the diaphragm to be " $95 \%$ to $99 \%$ effective and reversible," to entail "possible minor side effects," and to be "obtainable over the counter at a drugstore," then the diaphragm is assigned the evaluation computed for the hypothetical multiattribute contraceptive with that description.

Third, the validity of the beliefs about the real birth control methods is ascertained by computing the correlation between the ranking of the nine birth control methods (obtained in the real birth control ranking task) and the evaluations of the hypothetical contraceptives matched to those methods. The evaluations of the hypothetical contraceptives are by definition a function only of the composition rule and the values of the respondent, because the "beliefs" or attribute levels are specified in the hypothetical descriptions. In contrast, the ranking of the real birth control methods is a function of the respondent's

Relative Importance Percentage
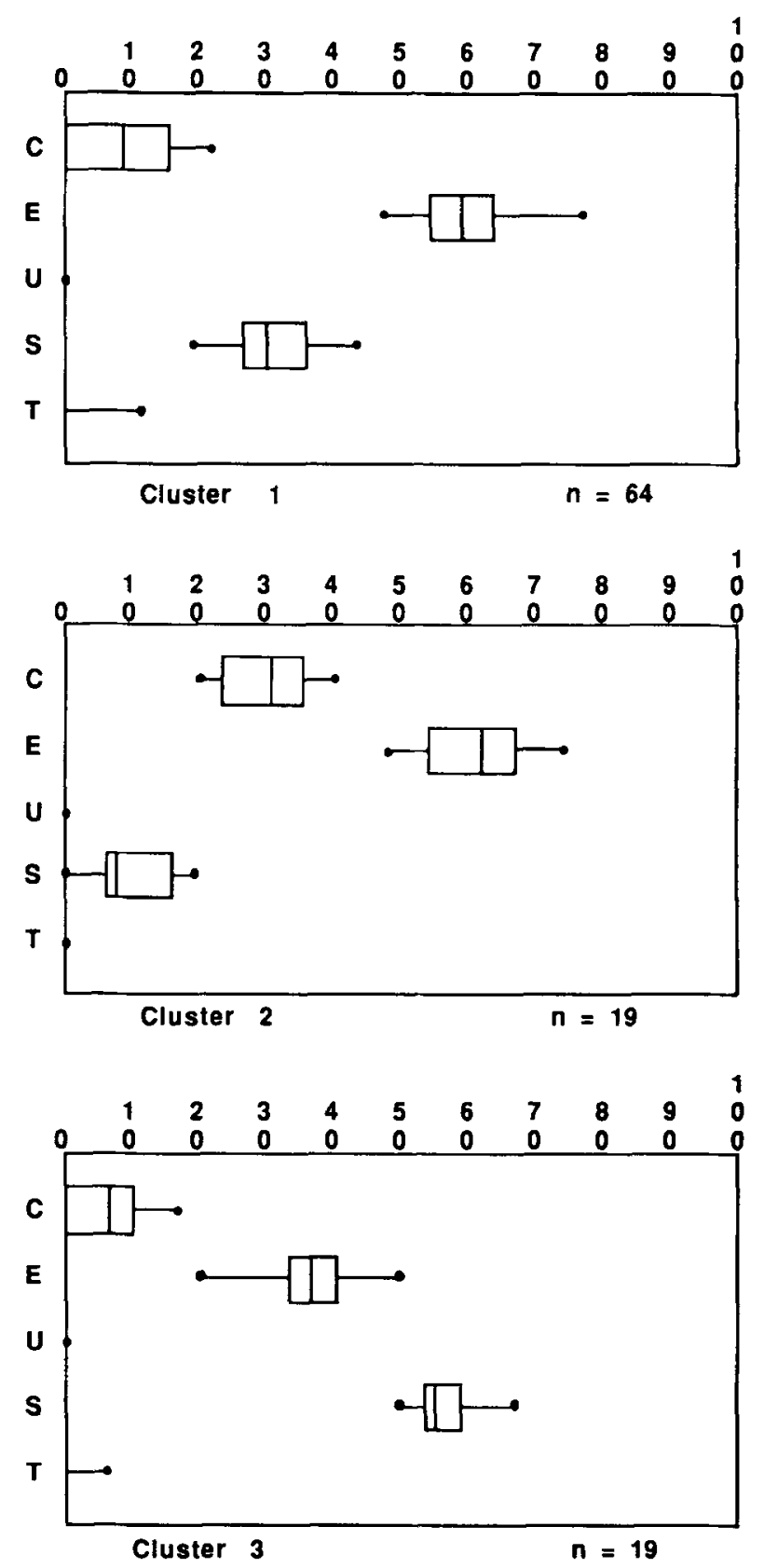

Figure 1. Box-and-whisker plots of attribute values for the three largest clusters of respondents $(C=$ convenience, $E=$ effectivenessreversibility, $U=$ use, $S=$ side effects, $T=$ type). 
composition rule and values, and of his or her beliefs about the attributes of each birth control method. If it is assumed that the respondent uses the same composition rule and values in rank ordering both the real methods and the hypothetical contraceptives, then this correlation constitutes a test of the accuracy of the attributes and attribute levels used in this study for describing the respondent's beliefs about the real birth control methods.

The Goodman-Kruskal (1954) gamma correlation coefficient for rank order data with ties was used to assess belief validity for the 128 respondents for whom composition rules could be determined. The median gamma correlation equals .63. Standard tests of significance are not appropriate for within-individual analyses; therefore, a gamma coefficient of .50 was arbitrarily selected to be "acceptable." The rationale for this selection is that this value assures that at least $75 \%$ of all possible pair comparisons in the two rankings have the same ordering or are tied. Eighty-three of the 128 respondents $(65 \%)$ have an acceptable gamma correlation coefficient, with a median of .75.

Table 4 presents the beliefs about the nine real birth control methods for the 83 respondents with acceptable gamma coefficients. It shows that there are, in most instances, great individual differences in respondents' beliefs about the attributes of the real birth control methods. All nine methods show substantial variation in believed level of convenience. With the exception of tubal ligation and vasectomy, which nearly all respondents believe to be " $98 \%$ to $100 \%$ effective and not reversible," the birth control methods show a fair amount of variation in believed effectiveness-reversibility. There is also substantial variation in the degree of side effects believed to be associated with all methods except the condom and periodic abstinence, which nearly all respondents agree entail "none/minor side effects." The only attribute of real birth control methods about which respondents agree is type; for all methods except the pill, respondents are unanimous or nearly so with respect to the type of a birth control method. There is a bit of disagreement as to whether the pill "can be obtained over the counter at a drugstore" or "requires a visit to a physician or clinic." Beliefs about use of the real birth control methods cannot be assessed because for no respondent with an acceptable gamma correlation coefficient is use both a chosen and essential attribute.

\section{Prediction}

The correlation between the evaluations of the hypothetical contraceptives and the ranking of the real birth control methods was described above as being a test of the validity of the attributes and attribute levels used. This correlation actually reflects both the accuracy of the attributes and attribute levels in describing a respondent's beliefs about the real birth control methods and the degree to which the respondent's beliefs, values, and composition rule predict his or her preferences across the nine real birth control methods. This is so because the course of analysis is a funnel-like procedure involving a sequence of analytic steps. If one of the steps in the sequence cannot be performed for a respondent, then analysis proceeds no further for that respondent. The validation of beliefs is the last step in the sequence; hence, if the gamma correlation coefficient validates beliefs, then prediction of a respondent's preferences from his or her beliefs, values, and composition rule has been successful also. Thus, the individual preference models developed using each respondent's contraceptive beliefs, values, and composition rule are able to predict preferences for real birth control methods for 83 respondents. This number constitutes 53\% of the total number of respondents in the sample and $65 \%$ of the respondents for whom composition rules could be classified.

\section{DISCUSSION}

The results of this study clearly show that there are substantial individual differences in contraceptive val-

Table 4

Beliefs about the Nine Real Birth Control Methods

\begin{tabular}{|c|c|c|c|c|c|c|c|c|c|c|c|c|c|}
\hline \multirow[b]{2}{*}{ Birth Control Method } & \multicolumn{3}{|c|}{ Convenience } & \multicolumn{3}{|c|}{$\begin{array}{l}\text { Effectiveness- } \\
\text { Reversibility }\end{array}$} & \multicolumn{3}{|c|}{ Side Effects } & \multicolumn{4}{|c|}{ Type } \\
\hline & 1 & 2 & 3 & 1 & 2 & 3 & 1 & 2 & 3 & 1 & 2 & 3 & 4 \\
\hline Tubal ligation & 68 & 13 & 19 & 95 & 5 & 0 & 43 & 38 & 19 & 100 & 0 & 0 & 0 \\
\hline Intrauterine device & 56 & 35 & 9 & 3 & 81 & 16 & 8 & 28 & 64 & 0 & 100 & 0 & 0 \\
\hline Vasectomy & 68 & 17 & 15 & 95 & 4 & 1 & 52 & 30 & 18 & 100 & 0 & 0 & 0 \\
\hline Pill & 68 & 30 & 2 & 3 & 88 & 9 & 12 & 37 & 51 & 0 & 85 & 15 & 0 \\
\hline Condom & 11 & 52 & 37 & 0 & 32 & 68 & 95 & 5 & 0 & 0 & 0 & 100 & 0 \\
\hline Diaphragm & 4 & 72 & 24 & 1 & 58 & 41 & 67 & 26 & 7 & 0 & 92 & 8 & 0 \\
\hline Foam/cream/jelly & 6 & 41 & 53 & 0 & 10 & 90 & 65 & 34 & 1 & 0 & 0 & 100 & 0 \\
\hline Periodic abstinence & 13 & 41 & 46 & 0 & 12 & 88 & 93 & 7 & 0 & 0 & 0 & 0 & 100 \\
\hline Condom with & 4 & 32 & 64 & 1 & 70 & 29 & 62 & 35 & 3 & 0 & 0 & 100 & 0 \\
\hline
\end{tabular}

Note-Table entries are percentages of the 83 respondents with acceptable gammas who described each real birth control method in terms of a particular level of each attribute. Only respondents for whom an attribute is both chosen and essential are included in the percentages for each attribute $(n=54,79,74$, and 13 for convenience, effectivenessreversibility, side effects, and type, respectively). There are no respondents with acceptable gammas for whom use is both a chosen and essential attribute. 
ues, beliefs, and composition rules even among a sociodemographically homogeneous group of respondents. Such individual differences undoubtedly exist for other consumer products and services as well. The existence of these individual differences creates methodological problems for the modeling of multiattribute preferences via conjoint analysis. The three strategies of tailoring, belief matching, and axiom testing were proposed as solutions to these problems. This discussion first evaluates the enhanced conjoint analysis methodology and then notes that the proposed solutions should also be useful in functional measurement studies.

\section{Evaluation of Methodology}

As noted above, use of a methodology in which conjoint analysis was enhanced with the techniques of tailoring, belief matching, and axiom testing resulted in the accurate modeling of the contraceptive preferences of 83 of the 156 respondents $(53 \%)$ in the study. The median gamma correlation predicting preferences for real birth control methods from contraceptive beliefs, values, and composition rules was .75 for these respondents. These figures seem reasonable in light of the fact that respondents were not screened for contraceptive use, intended use, or familiarity prior to participation in the study. Although contraception is a relevant issue for college students in general, it is undoubtedly not a relevant issue for every individual college student. Better prediction might have been achieved had respondents been, for instance, students visiting the university birth-control clinic.

It is useful to compare these figures with the results of other contraception studies. Although consumer researchers have virtually ignored the area of contraceptive preference (but see Downs, 1977, Weitz and Wright, 1979, and Wright and Weitz, 1977, for three exceptions), social and population psychologists have long been interested in the prediction of contraceptive use or contraceptive use-intention (e.g., Cohen et al., 1978; Davidson \& Jaccard, 1975; Fishbein \& Jaccard, 1973; Jaccard \& Davidson, 1972; Werner \& Middlestadt, 1979). Their studies generally consider the impact of both beliefs and values on contraceptive behavior; however, they differ from the present study in that they do not model the preferences or intentions of individuals, nor do they predict preferences or intentions across a number of contraceptive alternatives. Instead, predictions of contraceptive use or contraceptive use-intention are made for contraception in general or for a single specific contraceptive method such as the pill (e.g., Davidson \& Jaccard, 1975). These studies generally obtain a single across-respondents correlation of about .50 to .85 predicting contraceptive use or useintention from contraceptive beliefs and values. The results of the present study are within this range. It is worth noting, however, that these studies typically assess beliefs and values for 10 to 25 attributes and one contraceptive method, whereas in the present study, only two or three attributes were needed to reach about the same level of predictive accuracy across nine methods. One great advantage of the methodology used in the present study would thus appear to be its parsimony.

Traditional conjoint analysis typically assumes that all respondents use an additive composition rule over all product attributes included in the study. This assumption was warranted for only 73 of the $156(47 \%)$ respondents in the present study. Although the argument has been made that conjoint analysis performs at least as well as axiomatic conjoint measurement in detecting error or violations of the assumed composition rule (Emery \& Barron, 1979), evidence is accumulating that this is not so. Unfortunately, the presence of error or an incorrectly diagnosed composition rule can result in estimated values that are quite inaccurate. Preceding conjoint analysis with axiom testing and correcting errors as necessary helps prevent the misestimation of values.

The inability to determine composition rules for one fifth of the respondents in this study is troublesome but does not necessarily imply inadequacy of either the cardordering task or the axiom-testing methodology; it may simply reflect the fact that the contraceptive decision is a difficult one to make for some individuals. There may have been a few respondents for whom the card-ordering task was just too difficult, even though it was refined over several pilot studies to be as easy as possible and no respondent complained. However, close examination of the error patterns in the preference rank orderings of those respondents for whom composition rules could not be determined suggests at least two alternative explanations. First, many respondents simply seemed unclear about their contraceptive values, perhaps as a result of never having given much thought to the matter of choosing a method of birth control. Other respondents seemed to know what they like, and also what they don't like, but had difficulty choosing among the mediocre alternatives in between, all of which were characterized by a less-thandesirable level of at least one attribute. Perhaps axiomatic conjoint measurement's inability to determine a composition rule for these respondents should be considered an advantage of the methodology and not a flaw: Should nice neat preference models be created for respondents who don't seem to have nice neat preferences?

It is worth noting that even though the elimination criterion used here was more stringent, the number of respondents eliminated from further analysis via axiom testing compares favorably with the number of respondents eliminated on the basis of the stress measure in studies using only conjoint analysis to model preferences. For example, in a study of consumer preferences for shopping discount cards, $49 \%$ of the respondents' data sets obtained a stress value greater than .10 , the usual criterion for rejection of the proposed additive composition rule (Green, Carmone, \& Wind, 1972), and in a study of consumer preferences for restaurant menus, $30 \%$ of the respondents' data sets obtained stress values greater than .10 (Green \& Wind, 1973, p. 171).

The percentage of respondents for whom the attributes and attribute levels used in this study do not capture be- 
liefs about real birth control methods is rather disconcertingly high, particularly given the educational level of the respondents. The reason for this is not clear. It may be due to respondents' having received inaccurate information about specific contraceptive methods; in her review of adolescent contraceptive behavior, Morrison (1985) noted that adolescents' contraceptive information is more likely to come from peers and books and other media than from medical sources, sex education classes, or parents, and that peer information is often of poor quality. It may be due to lack of information rather than to misinformation, or to lack of experience; respondents were not screened for either sexual or contraceptive experience, and even those respondents who had used or were currently using contraception could have had, at most, only very short contraceptive careers. A third possibility is that respondents may not have been offered the opportunity to select those attributes that they consider most important in choosing a contraceptive method; Morrison (1985) noted that in addition to traditional contraceptive concerns such as effectiveness, safety, and convenience, adolescents also have concerns peculiar to their age group such as feelings of guilt, fear of discovery, feelings of embarrassment, and so on.

A study predicting preferences from beliefs and values should include all of the attributes actually considered by respondents and the attribute levels that best describe their beliefs about real products. Failure to capture contraceptive beliefs for $35 \%$ of the respondents for whom composition rules could be determined suggests that each respondent must be allowed to select his or her two or three (or perhaps four) most important attributes from a larger pool of attributes than was provided in this study. ${ }^{4}$ It also suggests that it may be necessary to tailor attribute levels as well as attributes to each individual respondent if good prediction is to be achieved. This "double tailoring" approach would not be feasible with the pencil-and-paper and card-ordering tasks used in this study; it would require an on-line interactive computer program for alternative generation and presentation and data collection. Such programs have been used successfully in commercial applications of conjoint analysis (Cattin \& Wittink, 1982).

The use of an interactive program offers several advantages in addition to that of tailoring attributes and attribute levels. These include (1) speed of data collection, (2) maintenance of respondent interest, (3) elimination of data entry from questionnaires to computer files prior to data analysis, and (4) the possibility of providing the respondent with immediate feedback about his or her beliefs and values. The availability of immediate feedback suggests that such a program would be useful not only as a research tool but also as a decision aid. For example, in the contraceptive situation, the program could be used in a family-planning clinic to assist the individual in selecting the best contraceptive method for personal use and to enhance his or her understanding of, commit- ment to, and effective use of that method (Sachs \& Pitz, 1981; Wall, 1985).

\section{Use with Functional Measurement}

Empirical applications of either axiomatic conjoint measurement or conjoint analysis are not common in psychological research. Just why such a useful and powerful methodology is so rarely employed is not clear; the claim is often made that conjoint measurement is not very practical because it lacks a formal error theory. Lack of an error theory, however, has not prevented widespread use of such techniques as factor analysis, cluster analysis, and multidimensional scaling. The popularity of functional measurement (Anderson, 1981, 1982b) in psychology suggests a more likely reason: Most researchers in psychology are either unfamiliar with or uncomfortable with an approach to data analysis that deviates from the multiple regression/analysis of variance paradigm that has dominated psychological research for so long (Cliff, 1973).

Functional measurement (Anderson, 1981, 1982b) is similar to axiomatic conjoint measurement in that it (1) generates choice alternatives through the factorial or fractional factorial combination of different levels of attributes and (2) derives values for those attributes subsequent to the validation of a proposed composition rule (called the "integration rule"). It differs in that (1) respondents are asked to assign numerical evaluations to the choice alternatives rather than to rank order them and (2) standard analysis of variance techniques are used to test proposed composition rules and derive values. In conjoint techniques, the attributes studied are usually characteristics of consumer products or services, whereas in functional measurement, the attributes are usually characteristics or consequences of behavioral or psychological phenomena. This difference, however, is not dictated by the methodologies themselves but reflects their usual applications: Conjoint techniques are used most often by consumer researchers, and functional measurement is used most often by psychologists. However, conjoint techniques can be, and have been, used to study psychological phenomena (e.g., C. H. Coombs \& Bowen, 1971, and C. H. Coombs \& Huang, 1970, on the perceived riskiness of gambles; C. H. Coombs et al., 1975, on familysize and sex-composition preferences; L. C. Coombs, 1979, on job/family preferences; Fischer, 1976, on joboffer preferences; Nygren, 1985, on workload preferences; Orkin \& Greenhow, 1978, on the competence of medical residents; Ullrich \& Painter, 1974, on jobapplicant preferences; Wallsten, 1972, 1976, on probabilistic information processing; Wallsten \& Budescu, 1981, on the assessment of personality profiles; and Wittink \& Montgomery, 1979, on job preferences). Likewise, functional measurement can be, and has been, used to study preferences for consumer goods and services (e.g., Bettman, Capon, \& Lutz, 1975a, 1975b, on toothpaste preferences; Kocur, Hyman, \& Aunet, 1982, Lerman \& Louviere, 1978, Levin \& Herring, 1981, Norman, 1977, 
and Norman \& Louviere, 1974, on transportation and travel preferences; Meyer, 1982, on preferences for pizza parlors and apartments; and Troutman \& Shanteau, 1976, on preferences for disposable diapers and infant car seats).

The question then arises as to which of the two methodologies is "better." There has been extensive and acrimonious debate about the relative merits of the two approaches. Critics of axiomatic conjoint measurement emphasize its lack of an error theory; critics of functional measurement question whether the numerical evaluations assigned by respondents to the choice alternatives can be regarded as the interval-scale measurements required by analysis of variance. We do not intend to reopen this debate; the interested reader is referred to Anderson (1981, pp. 347-356, 378-380; 1982a; 1982b, pp. 220-226), Birnbaum (1982), Cliff (1973), Dawes and Smith (1985), Falmagne (1976), Krantz et al. (1971, pp. 445-447), Krantz and Tversky (1971), and the exchange of letters in The Psychological Review (Anderson, Krantz, \& Tversky, 1971), and invited to draw his or her own conclusions. We note, however, that two of the three methodological problems encountered in implementing conjoint analysis - the problems of an overly large set of choice alternatives and the hypothetical nature of the alternatives in the choice set-also occur in implementing functional measurement, and that the suggested solutions of tailoring and belief matching, used here in a conjoint analysis study, can be used in functional measurement studies as well (e.g., Jaccard \& Becker, 1985). In fact, because rating-scale tasks are easier to present on computerterminal screens than rank-ordering tasks, functional measurement would be particularly useful in implementing the "double tailoring" approach described above.

\section{REFERENCES}

Abelson, R. P., \& LeVI, A. (1985). Decision making and decision theory. In G. Lindzey \& E. Aronson (Eds.), Handbook of social psychology (3rd ed., Vol. 1, pp. 231-309). New York: Random House.

ANDERSON, N. H. (1981). Foundations of information integration theory. New York: Academic Press.

ANDERson, N. H. (1982a). Cognitive algebra and social psychophysics. In B. Wegener (Ed.), Social attitudes and psychophysical measurement (pp. 123-148). Hillsdale, NJ: Erlbaum.

ANDERSON, N. H. (1982b). Methods of information integration theory. New York: Academic Press.

Anderson, N. H., Krantz, D. H., \& Tversky, A. (1971). An exchange on functional and conjoint measurement [Letters to the Editor]. Psychological Review, 78, 457-458.

Anderson, N. H., \& Shanteau, J. (1977). Weak inference with linear models. Psychological Bulletin, 84, 1155-1170.

ANscombe, F. J. (1973). Graphs in statistical analysis. American Statistician, 27, 17-21.

Barron, F. H. (1977). Axiomatic conjoint measurement. Decision Sciences, 8, 548-559.

Bettman, J. R., Capon, N., \&utz, R. J. (1975a). Cognitive algebra in multi-attribute attitude models. Joumal of Marketing Research, 12, 151-164.

Bettman, J. R., Capon, N., \& Lutz, R. J. (1975b). Multiattribute measurement models and multiattribute attitude theory: A test of construct validity. Journal of Consumer Research, 1, 1-15.
Birnbaum, M. H. (1973). The devil rides again: Correlation as an index of fit. Psychological Bulletin, 79, 239-242.

BirNbaum, M. H. (1982). Controversies in psychological measurement. In B. Wegener (Ed.), Social attitudes and psychophysical measurement (pp. 401-485). Hillsdale, NJ: Erlbaum.

Boston Women's Health Book Collective. (1976). Our bodies, ourselves. New York: Simon \& Schuster.

BUSEMEYER, J. R. (1980). Importance of measurement theory, error theory, and experimental design for testing the significance of interactions. Psychological Bulletin, 88, 237-244.

Campbell, A. A., \& Berelson, B. (1971). Contraceptive specifications: Report on a workshop. Studies in Family Planning, 2, 14-19.

CARroll, J. D. (1973). Appendix B: Models and algorithms for multidimensional scaling, conjoint measurement, and related techniques. In P. E. Green \& Y. Wind, Multiattribute decisions in marketing: A measurement approach (pp. 299-371). Hinsdale, IL: Dryden Press.

Cattin, P., \& Wittink, D. R. (1982). Commercial use of conjoint analysis: A survey. Journal of Marketing, 46, 44-53.

Cuif,, N. (1973). Scaling. Annual Review of Psychology, 24, 473-506.

Cohen, J. B., Severy, L. J., \& Ahtola, O. T. (1978). An extended expectancy-value approach to contraceptive alternatives. Journal of Population, 1, 22-41.

COOMBs, C. H., \& Bowen, J. N. (1971). A test of VE-theories of risk and the effect of the central limit theorem. Acta Psychologica, 35 , $15-28$.

Coombs, C. H., Coombs, L. C., \& McClelland, G. H. (1975). Preference scales for number and sex of children. Population Studies, 29. 273-298.

COOmbs, C. H., Dawes, R. M., \& TVersky, A. (1970). Mathematical psychology: An elementary introduction. Englewood Cliffs, NJ: Prentice-Hall.

Coombs, C. H., \& Huang, L. C. (1970). Polynomial psychophysics of risk. Journal of Mathematical Psychology, 7, 317-338.

CoOmBs, L. C. (1979). The measurement of commitment to work. Journal of Population, 2, 203-223.

Curley, S. P. (1990). Practical application of axiomatic conjoint measurement. Manuscript submitted for publication.

Darlington, R. B. (1968). Multiple regression in psychological research and practice. Psychological Bulletin, 69, 161-182.

Davidson, A. R., \& JacCARD, J. J. (1975). Population psychology: A new look at an old problem. Journal of Personality \& Social Psychology, 31, 1073-1082.

DAwEs, R. M., \& CoRRIGAN, B. (1974). Linear models in decision making. Psychological Bulletin, 81, 95-106.

DAwES, R. M., SMiтh, T. L. (1985). Attitude and opinion measurement. In G. Lindzey \& E. Aronson (Eds.), Handbook of social psychology (3rd ed., Vol. 1, pp. 509-566). New York: Random House.

de Leeuw, J., Young, F. W., \& Takane, Y. (1976). Additive structure in qualitative data: An alternating least squares method with optimal scaling features. Psychometrika, 41, 471-503.

Dixon, W. J., \& BRown, M. B. (Eds.) (1977). BMDP-77; Biomedical computer programs, $P$ series. Berkeley: University of California Press.

Downs, P. E. (1977). Intrafamily decision making in family planning. Journal of Business Research, 5, 63-74.

Einhorn, H. J., Kleinmuntz, D. N., \& Kleinmuntz, B. (1979). Linear regression and process-tracing models of judgment. Psychological Review, 86, 465-485.

EMERY, D. R. (1977a). DIST: A numerical conjoint measurement program designed to scale data to a distributive model in three dimensions. Journal of Marketing Research, 14, 413-414.

EMERY, D. R. (1977b). DULST: A numerical conjoint measurement program designed to scale data to a dual-distributive model in three dimensions. Journal of Marketing Research, 14, 558-559.

EMERY, D. R. (1978). Optimal scaling via ordinary least squares (Working Paper No. WP-31-78). Alberta, Canada: University of Calgary, School of Business, Faculty of Management.

EMERY, D. R., \& BARRON, F. H. (1979). Axiomatic and numerical conjoint measurement: An evaluation of diagnostic efficacy. Psychometrika, 44, 195-210. 
FalmaGne, J.-C. (1976). Random conjoint measurement and loudness summation. Psychological Review, 83, 65-79.

Fischer, G. W. (1976). Multidimensional utility models for risky and riskless choice. Organizational Behavior \& Human Performance, 17, 127-146.

Fishbein, M. (1967). A behavior theory approach to the relations between beliefs about an object and the attitude toward the object. In $\mathrm{M}$. Fishbein (Ed.), Readings in attitude theory and measurement (pp. 389-400). New York: Wiley.

Fishbein, M., \& JCCARD, J. J. (1973). Theoretical and methodological considerations in the prediction of family planning intentions and behavior. Representative Research in Social Psychology, 4(1), 37-51.

Goodman, L. A., KRUSKal, W. H. (1954). Measures of association for cross classifications. Joumal of the American Statistical Association, 49, 732-764.

GrEeN, P. E. (1974). On the design of choice experiments involving multifactor alternatives. Journal of Consumer Research, 1, 61-68.

Green, P. E., Carmone, F. J., \& WINd, Y. (1972). Subjective evaluation models and conjoint measurement. Behavioral Science, 17. 288-299.

Green, P. E. RAO, V. R. (1971). Conjoint measurement for quantifying judgmental data. Journal of Marketing Research, 8, 355-363.

Green, P. E., Rao, V. R., DeSARbo, W. S. (1978). Incorporating group-level similarity judgments in conjoint analysis. Journal of Consumer Research, 5, 187-193.

Green, P. E., \& Srinivasan, V. (1978). Conjoint analysis in consumer research: Issues and outlook. Journal of Consumer Research, 5 , 103-123.

GREEN, P. E., \& WIND, Y. (1973). Multiattribute decisions in marketing: A measurement approach. Hinsdale, IL: Dryden Press.

GreEN, P. E., \& WiNd, Y. (1975). New way to measure consumers' judgments. Harvard Business Review, 53(4), 107-117.

HANSEN, F. (1969). Consumer choice behavior: An experimental approach. Journal of Marketing Research, 6, 436-443.

Holgrook, M. B., Moore, W. L., Dodgen, G. N., \& Havlena, W. J. (1985). Nonisomorphism, shadow features, and imputed preferences. Marketing Science, 4, 215-233.

Holt, J. O., W WLLSTEN, T. S. (1974). A user's manual for CONJOINT: A computer program for evaluating certain conjoint-measurement axioms (Tech. Rep. No. 42). Chapel Hill: University of North Carolina, L. L. Thurstone Psychometric Laboratory.

JACCARD, J. J., \& BECKER, M. A. (1985). Attitudes and behavior: An information integration perspective. Journal of Experimental Social Psychology, 21, 440-465.

JACCARD, J. J., \& DAviDSON, A. R. (1972). Toward an understanding of family planning behaviors: An initial investigation. Journal of Applied Social Psychology, 2, 228-235.

JoHNSON, R. M. (1975). A simple method for pairwise monotone regression. Psychometrika, 40, 163-168.

Judd, C. M., \& MCClelland, G. H. (1989). Data amalysis: A modelcomparison approach. San Diego; Harcourt Brace Jovanovich.

Kocur, G., Hyman, W., AUNeT, B. (1982). Wisconsin work modechoice models based on functional measurement and disaggregate behavioral data. Transportation Research Record, No. 895, 24-32.

Krantz, D. H., LuCE, R. D., SupPes, P., \& TVerSky, A. (1971). Foundations of measurement (Vol. 1). New York: Academic Press.

Krantz, D. H., \& Tversky, A. (1971). Conjoint-measurement analysis of composition rules in psychology. Psychological Review, 78, $151-169$

KrUSKAL, J. B. (1965). Analysis of factorial experiments by estimating monotone transformations of the data. Joumal of the Royal Statistical Society, 27B, 251-263.

LERMAN, S. R., \& LouviERE, J. J. (1978). Using functional measurement to identify the form of utility functions in travel demand models. Transportation Research Record, No. 673, 78-86.

Levin, I. P., Herring, R. D. (1981). Functional measurement of qualitative variables in mode choice: Ratings of economy, safety, and desirability of flying versus driving. Transportation Research, 15A, 207-214.

LOUVIERE, J. J. (1988). Analyzing decision making: Metric conjoint analysis. Newbury Park, CA: Sage Publications.
McClelland, G. (1977). A note on Arbuckle and Larimer, "The number of two-way tables satisfying certain additivity axioms. "Joumal of Mathematical Psychology, 15, 292-295.

McClelland, G. H., \& Coombs, C. H. (1975). ORDMET: A general algorithm for constructing all numerical solutions to ordered metric structures. Psychometrika, 40, 269-290.

MEYER, R. J. (1982). A descriptive model of consumer information search behavior. Marketing Science, 1, 93-121.

MOORE, W. L., \& Holbrook, M. B. (1982). On the predictive validity of joint-space models in consumer evaluations of new concepts Journal of Consumer Research, 9, 206-210.

Morrison, D. M. (1985). Adolescent contraceptive behavior: A review. Psychological Bulletin, 98, 538-568.

Nickerson, C. A., MCClelland, G. H. (1984). Scaling distortion in numerical conjoint measurement. Applied Psychological Measurement, 8, 183-198.

Nickerson, C. A., \& MCClelland, G. H. (1988). Extended axiomatic conjoint measurement: A solution to a methodological problem in studying fertility-related behaviors. Applied Psychological Measurement, 12, 129-153.

Nisbett, R. E., WiLSON, T. D. (1977). Telling more than we can know: Verbal reports on mental processes. Psychological Review, 84, 231-259.

NoRman, K. L. (1977). Attributes in bus transportation: Importance depends on trip purpose. Joumal of Applied Psychology, 62, 164-170.

NoRmaN, K. L., LOUVIERE, J. J. (1974). Integration of attributes in bus transportation: Two modeling approaches. Journal of Applied Psychology, 59, 753-758.

Nygren, T, E. (1980). Limitations of additive conjoint scaling procedures: Detecting nonadditivity when additivity is known to be violated. Applied Psychological Measurement, 4, 367-383.

NyGREN, T. E. (1985). An examination of conditional violations of axioms for additive conjoint measurement. Applied Psychological Measurement, 9, 249-264.

NyGREN, T. E. (1986). A two-stage algorithm for assessing violations of additivity via axiomatic and numerical conjoint analysis. Psychometrika, 51, 483-491.

Orkin, F. K., GREENhow, D. E. (1978). A study of decision making: How faculty define competence. Anesthesiology, 48, 267-271

Parker, B. R., \& Srinivasan, V. (1976). A consumer preference approach to the planning of rural primary health-care facilities. Operations Research, 24, 991-1025.

Polgar, S. \& Marshall, J. F. (1976). The search for culturally acceptable fertility regulating methods. In J. F. Marshall \& S. Polgar (Eds.), Culture, natality, and family planning (pp. 204-218). Chapel Hill, NC: Carolina Population Center.

ROSKAM, E. E. (1974). Unidimensional conjoint measurement (UNICON) for multi-faceted designs. Nijmegen, The Netherlands: University of Nijmegen, Psychologisch Laboratorium.

SACHS, N. J., \& PITZ, G. F. (1981). Choosing the best method of contraception: Application of decision analysis to contraceptive counseling and selection. Unpublished manuscript, Southern Illinois University, Carbondale.

SALYER, S. L., \& BAUSCH, J. J. (1978), Toward safe, convenient, and effective contraceptives: A policy perspective. New York: The Population Council.

SCHMitT, N., \& Levine, R. L. (1977). Statistical and subjective weights: Some problems and proposals. Organizational Behavior \& Human Performance, 20, 15-30.

Schuler, H. J., \& Prosperi, D. C. (1978). A conjoint measurement model of consumer spatial behavior. Regional Science Perspectives, 8, 122-134.

Shanteau, J. (1977). Correlation as a deceiving measure of fit. Bulletin of the Psychonomic Society, 10, 134-136.

Slovic, P., Lichtenstein, S. (1971). Comparison of Bayesian and regression approaches to the study of information processing in judgment. Organizational Behavior \& Human Performance, 6, 649-744.

SRINIVASAN, V., ShOCKER, A. D. (1973). Linear programming techniques for multidimensional analysis of preferences. Psychometrika, 38, 337-369.

TAKANE, Y. (1978), A maximum likelihood method for nonmetric multi- 
dimensional scaling: I. The case in which all empirical pairwise orderings are independent-Theory. Japanese Psychological Research, 20. 7-17.

Timmermans, H. (1980). Unidimensional conjoint measurement models and consumer decision-making. Area (Publication of the Institute of British Geographers), 12, 291-300.

Troutman, C. M., \& Shanteau, J. (1976). Do consumers evaluate products by adding or averaging attribute information? Jourmal of Consumer Research, 3, 101-106.

TUKEY, J. W. (1977). Exploratory data analysis. Reading, MA: Addison-Wesley.

Ullrich, J. R., \& Cummins, D. E. (1973). PCJM: A program for conjoint measurement analysis of polynomial composition rules. Behavioral Science, 18, 226-227.

Ullrich, J. R., Cummins, D. E., \& WalkenbaCh, J. (1978). PCJM2: A program for the axiomatic conjoint measurement analysis of polynomial composition rules. Behavior Research Methods \& Instrumentation, 10, 89-90.

Ullrich, J. R., \& Painter, J. R. (1974). A conjoint-measurement analysis of human judgment. Organizational Behavior \& Human Performance, 12, 50-61.

WALL, E. M. (1985). Development of a decision aid for women choosing a method of birth control. Journal of Family Practice, 21, 351-355.

WALLSTEN, T. S. (1972). Conjoint-measurement framework for the study of probabilistic information processing. Psychological Review, 79, 245-260.

WALLSTEN, T. S. (1976). Using conjoint-measurement models to investigate a theory about probabilistic information processing. Journal of Mathematical Psychology, 14, 144-185.

W AlLSTEN, T. S., \& BUDESCU, D. V. (1981). Additivity and nonadditivity in judging MMPI profiles. Journal of Experimental Psychology: Human Perception \& Performance, 7, 1096-1109.

WeITZ, B., \& WRIGHT, P. (1979). Retrospective self-insight on factors considered in product evaluation. Journal of Consumer Research, 6, 280-294.

Werner, P. D., \& Middlestadt, S. E. (1979). Factors in the use of oral contraceptives by young women. Journal of Applied Social Psychology, 9, 537-547.

Wilkie, W. L., \& WeINREICh, R. P. (1972). Effects of the number and type of attributes included in an attitude model: More is not better. In M. Venkatesan (Ed.), Proceedings of the Third Annual Conference of the Association for Consumer Research (pp. 325-340). College Park, MD: Association for Consumer Research.

Wittink, D. R., Montgomery, D. B. (1979). Predictive validity of trade-off analysis for alternative segmentation schemes. In N. Beckwith, M. Houston, R. Mittelstaedt, K. B. Monroe, \& S. Ward (Eds.), 1979 Educators' Conference Proceedings (pp. 69-73). Chicago: American Marketing Association.

WRIGHT, P., \& WITZ, B. (1977). Time horizon effects on product evaluation strategies. Journal of Marketing Research, 14, 429-443.

YNTEMA, D. B., \& Torgerson, W. S. (1961). Man-computer cooperation in decisions requiring common sense. IRE Transactions on Human Factors in Electronics, HFE-2[1], 20-26.

YoUNG, F. W. (1972). A model for polynomial conjoint analysis algorithms. In R. N. Shepard, A. K. Romney, \& S. B. Nerlove (Eds.), Multidimensional scaling: Theory and applications in the behavioral sciences (Vol. 1, pp. 69-104). New York: Seminar Press.
ZeLENY, M. (1976). On the inadequacy of the regression paradigm used in the study of human judgment. Theory \& Decision, 7, 57-65.

\section{NOTES}

1. In the absence of "signed" attributes, however, multiplicative rules are not distinguishable from additive rules. A signed attribute is one that has a natural zero or neutral level; levels on either side of the neutral level are negatively and positively valued, respectively. The contraceptive attributes used in this study are not signed.

2. Higher ranks indicate greater preference.

3. For some reason, the correction of data errors (e.g., eliminating outliers) is often viewed in the social sciences as "cheating" or "fudging." even though it is well known that such errors can have undue and extraordinary influence on the results of a data analysis, particularly when the total number of observations in the data set is small. (See Anscombe, 1973, for some compelling examples in regression analysis.) Although there is no doubt that procedures for error detection and elimination or correction can be abused, we think that it is more honest to eliminate or correct such errors and thereby allow the results to be based on the majority of the data observations than it is to ignore them and present results that may be grossly distorted (Judd \& McClelland, 1989. pp. 231-232).

4. One problem with the tailoring approach is that it presumes that individuals know enough about their own values to be able to select the two or three product attributes most important to them. The fact that a number of respondents selected attributes that analysis showed to be irrelevant to their preferences suggests that some individuals do not possess this self-knowledge. In fact, there exists a fair amount of empirical evidence that individuals tend to overestimate the importance of lessvalued attributes (Einhorn, Kleinmuntz, \& Kleinmuntz, 1979; Schmitt \& Levine, 1977; Slovic \& Lichtenstein, 1971). Even more troublesome is the possibility that a respondent may fail to select an attribute that has great influence on his or her preferences. These possibilities create a methodological dilemma: cognitive psychology suggests that individuals are not able to consider more than a few attributes, but there may be a large set of possible attributes that might affect any given individual's preferences. Furthermore, different individuals may consider different subsets of the total set of attributes. How can the appropriate set of attributes be selected for each respondent? There is no guarantee that a respondent is able to select the few attributes that affect his or her preferences. On the other hand, there is no guarantee that the researcher is able to select those attributes either (although the vast majority of studies of multiattribute preferences have used attributes selected by the researcher). We don't know the solution to this dilemma, but we will note that if the selected attributes are not the ones that are affecting the respondent's preferences for real alternatives, then the correlation between the evaluations of the hypothetical multiattribute alternatives and the ranking of the real alternatives should be low for that respondent. It should be noted that the question of self-knowledge bedevils many other methodologies used in psychology. For example, verbal protocol analysis assumes that a respondent both knows and can describe what he or she is doing in a problem-solving task, an assumption that has been much disputed (Nisbett \& Wilson, 1977).

(Manuscript received April 5, 1990; revision accepted for publication July 16,1990 .) 